\title{
Dynapenia could predict chemotherapy- induced dose-limiting neurotoxicity in digestive cancer patients
}

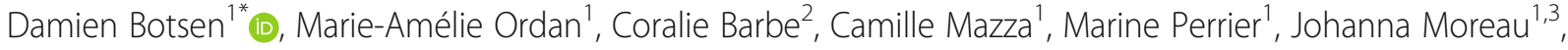
Mathilde Brasseur ${ }^{1,3}$, Yohann Renard ${ }^{4}$, Barbara Taillière ${ }^{5}$, Florian Slimano ${ }^{1}$, Eric Bertin ${ }^{6}$ and Olivier Bouché ${ }^{1,3}$

\begin{abstract}
Background: FIGHTDIGO study showed the feasibility and acceptability of handgrip strength (HGS) measure in routine in 201 consecutive patients with digestive cancer treated with ambulatory chemotherapy. The present study focuses on the second aim of FIGHTDIGO study: the relationships between pre-therapeutic dynapenia and chemotherapy-induced Dose-Limiting Toxicities (DLT).

Methods: In this ancillary prospective study, DLT were analyzed in a sub-group of 45 chemotherapy-naive patients. Two bilateral consecutive measures of HGS were performed with a Jamar dynamometer before the first cycle of chemotherapy. Dynapenia was defined as HGS $<30 \mathrm{~kg}$ (men) and $<20 \mathrm{~kg}$ (women). DLT and/or Dose-Limiting Neurotoxicity (DLN) were defined as any toxicity leading to dose reduction, treatment delays or permanent treatment discontinuation.

Results: Two-thirds of chemotherapies were potentially neurotoxic $(n=31$ [68.7\%]) and 22 patients (48.9\%) received FOLFOX (5FU, leucovorin plus oxaliplatin) regimen chemotherapy. Eleven patients (24.4\%) had pre-therapeutic dynapenia. The median number of chemotherapy cycles was 10 with a median follow-up of 167 days. Twenty-two patients experienced DLT (48.9\%). There was no significant association between pre-therapeutic dynapenia and DLT $(p=0.62)$. Nineteen patients (42.2\%) experienced DLN. In multivariate analysis, dynapenia and tumoral location (stomach, biliary tract or small intestine) were independent risk factors for DLN (HR=3.5 [1.3; 9.8]; $p=0.02$ and $H R=$ $3.6[1.3 ; 10.0] ; p=0.01$, respectively).
\end{abstract}

Conclusions: Digestive cancer patients with pre-therapeutic dynapenia seemed to experience more DLN. HGS routine measurement may be a way to screen patients with frailty marker (dynapenia) who would require chemotherapy dose adjustment and adapted physical activity programs.

Trial registration: NCT02797197 June 13, 2016 retrospectively registered.

Keywords: Dynapenia, Antineoplastic agents, Digestive system neoplasms, Sarcopenia, Dose-limiting toxicity, Muscle strength

\footnotetext{
* Correspondence: damien.botsen@gmail.com

${ }^{1}$ Ambulatory Cancer Unit, Reims University Hospital, Robert Debré Hospital,

rue du Général Koenig, 51100 Reims, France

Full list of author information is available at the end of the article
}

(c) The Author(s). 2018 Open Access This article is distributed under the terms of the Creative Commons Attribution 4.0 International License (http://creativecommons.org/licenses/by/4.0/), which permits unrestricted use, distribution, and reproduction in any medium, provided you give appropriate credit to the original author(s) and the source, provide a link to the Creative Commons license, and indicate if changes were made. The Creative Commons Public Domain Dedication waiver (http://creativecommons.org/publicdomain/zero/1.0/) applies to the data made available in this article, unless otherwise stated. 


\section{Background}

Digestive cancers represent most of cancer spectrum in the world [1] with cytotoxic drugs and targeted biotherapy mainly used. Cancer cachexia is a multifactorial syndrome defined by an ongoing loss of skeletal muscle (with or without loss of fat mass) that cannot be fully reversed by conventional nutritional support and leads to progressive functional impairment (loss of muscle strength) [2]. Sarcopenia is defined as the age-related loss in skeletal muscle mass, and function (dynapenia [3] or performance) [4, 5]. Historically, calculation of anti-cancer treatment dose used body surface area (BSA) formula [6] depending on patient's weight and height. However, the objective at this time was not to develop a formula to dose anti-cancer drugs. Furthermore, body composition has emerged as an important predictor of anti-cancer drug efficacy and toxicity [7-13]. In 2013, a systematic review led by Prado et al. has described a correlation between low lean tissue and severe toxicities of antineoplastic agents due to plasmatic surexposure [14]. A growing literature suggests that the lean tissue compartment may be used to adjust dosage of drugs that are distributed in and metabolized by lean tissues [14-17]. Loss of muscle mass occurs in $80 \%$ of patients with cancer [18] but cannot be interpreted without its function, that is muscle strength.

Handgrip Strength (HGS) has been validated in geriatric and surgical studies. In oncology, HGS is associated with cancer-related fatigue, poor quality of life, loss of functional status in hospitalized patients, postoperative complications, length of hospital stay and short term survival [19-23]. It has also been included in the consensual definition of sarcopenia, which associates muscle mass loss and weak strength [5]. Muscle mass is one of the determinants of muscle strength [24], but needs invasive and costly exams to be estimated (X-ray absorptiometry(DXA), anthropometry and bioelectrical impedance analysis (BIA), magnetic resonance imaging (MRI) or computerized tomography (CT)). HGS may be a low cost method to detect sarcopenia in clinical settings and by extrapolation to predict anticancer drug toxicity in patients with advanced cancers [25]. Recently, Ordan et al. [23] showed in FIGHTDIGO study the feasibility and acceptability of HGS measure with a Jamar dynamometer in routine. The present study focuses on the second aim of FIGHTDIGO study: the association between pre-therapeutic dynapenia and chemotherapy-induced Dose-Limiting Toxicities (DLT) in digestive cancer patients treated with ambulatory chemotherapy.

\section{Methods}

\section{Study design and participants}

This ancillary prospective monocentric study was conducted in the Ambulatory Cancer Unit (UMA-CH) of the Reims teaching hospital in France. The study population of FIGHTDIGO included patients older than 18 years-old, having a primary digestive cancer regardless of stage, and undergoing cytotoxic chemotherapy and/or biotherapy for digestive system cancers. All cytotoxic chemotherapy and/or biotherapy regimens according to guidelines were allowed. Patients who could not give their consent, did not understand the handgrip test, had history of neuro-muscular disorder and/or had appointed a health care proxy were excluded. The patients were recruited from May 18, 2016, to November 18,2016 , and were followed for 6 months. For this study on chemotherapy-induced DLT, in order to avoid an overestimation of toxicities in pre-treated patients, only the sub-group of chemotherapy-naive patients were included.

\section{Ethical approval}

Informed written consent was obtained for each enrolled patient in the trial. The FIGHTDIGO study was approved by the ethics committee (Committee for the Protection of Person EST I DIJON, 25 March 2016) and was registered in Clinicaltrials.gov (NCT02797197).

\section{Outcome}

The aim was to evaluate pre-therapeutic dynapenia as a predictive factor of chemotherapy-induced DLT and/or Dose-Limiting Neurotoxicity (DLN). Other potential predictive factors were analyzed (patient, tumoral, nutritional (as modified Glasgow Prognostic Score (mGPS)) and therapeutic characteristics).

\section{Handgrip strength (HGS) measurement}

HGS was measured, at first hospital stay, before chemotherapy administration, in non-dominant and dominant hand using a hydraulic Jamar Dynamometer. Position 2 was used among the 5 possible handle-positions. Patients performed the test while sitting comfortably (feet touching ground) with shoulder adducted, forearm neutrally rotated and elbow flexed to $90^{\circ}$. The other upper limb was placed alongside the body and relaxed. Patients were instructed (by physicians) to perform maximal isometric contraction within $3 \mathrm{~s}$ in both hand. Four measurements were taken. Two measurements were determined for each hand alternatively. A one-minute break was respected between two measurements with the same hand. The highest value (from the four measurements obtained) was chosen for final evaluation. According to the European Working Group on Sarcopenia, dynapenia was defined as HGS $<30 \mathrm{~kg}$ (men) and < $20 \mathrm{~kg}$ (women) [5]. 
Table 1 Baseline characteristics $(n=45)$

\begin{tabular}{|c|c|}
\hline Characteristics $^{a}$ & Value \\
\hline Age, mean $\pm S D$ & $66.2 \pm 12.3$ \\
\hline \multicolumn{2}{|l|}{ Sex } \\
\hline Male & $21(46.7)$ \\
\hline Female & $24(53.3)$ \\
\hline Body Mass Index, mean $\pm S D, \mathrm{~kg} / \mathrm{m}^{2}$ & $23.2 \pm 4.1$ \\
\hline \multicolumn{2}{|l|}{ BMI categories, No. (\%) } \\
\hline Malnutrition ${ }^{b}$ & $7(15.6)$ \\
\hline Normal & $24(53.3)$ \\
\hline Overweight ${ }^{c}$ & $14(31.1)$ \\
\hline \multicolumn{2}{|l|}{ ECOG PS, No. (\%) } \\
\hline 0 & $12(26.7)$ \\
\hline 1 & $31(68.9)$ \\
\hline 2 & $2(4.4)$ \\
\hline \multicolumn{2}{|l|}{ mGPS $^{d}$, No. (\%) } \\
\hline 0 & $17(43.6)$ \\
\hline 1 & 17(43.6) \\
\hline 2 & $5(12.8)$ \\
\hline Hospitalizations number, median [range] & $10[0-18]$ \\
\hline Follow-up, median [range], days & $167[0-189]$ \\
\hline \multicolumn{2}{|l|}{ Primary tumor location, No. (\%) } \\
\hline Colon and rectum & $22(48.9)$ \\
\hline Esophagus & $3(6.7)$ \\
\hline Stomach & $5(11.1)$ \\
\hline Biliary tract & $1(2.2)$ \\
\hline Pancreas & $9(20.0)$ \\
\hline Small intestine & $1(2.2)$ \\
\hline Neuroendocrine tumor & $2(4.4)$ \\
\hline Unknown & $2(4.4)$ \\
\hline \multicolumn{2}{|l|}{ Stage, No. (\%) } \\
\hline Local & $20(44.4)$ \\
\hline Locally advanced & $6(13.3)$ \\
\hline Metastatic & $19(42.2)$ \\
\hline \multicolumn{2}{|l|}{ Type of treatment, No. (\%) } \\
\hline Chemotherapy & $38(84.4)$ \\
\hline Chemotherapy and biotherapy & $7(15.6)$ \\
\hline \multicolumn{2}{|l|}{ Chemotherapy protocol, No. (\%) } \\
\hline $5 F U+$ OXALIPLATIN & $22(48.9)$ \\
\hline 5FU + IRINOTECAN + OXALIPLATIN & $7(15.6)$ \\
\hline $5 F U$ alone & $6(13.3)$ \\
\hline GEMCITABINE & $5(11.1)$ \\
\hline 5FU-DACARBAZINE & $2(4.4)$ \\
\hline $5 F U+I R I N O T E C A N$ & $1(2.2)$ \\
\hline GEMCITABINE + OXALIPLATIN & $1(2.2)$ \\
\hline VP16 + CISPLATINE & $1(2.2)$ \\
\hline
\end{tabular}

Table 1 Baseline characteristics $(n=45)$ (Continued)

\begin{tabular}{ll}
\hline Characteristics $^{\text {a }}$ & Value \\
\hline Neurotoxic chemotherapy & e, No. (\%) \\
Biotherapy protocol, No. (\%) & $31(68.9)$ \\
BEVACIZUMAB & $6 / 7(85.7)$ \\
CETUXIMAB & $1 / 7(14.3)$ \\
Dynapenia, No. (\%) & $11(24.4)$ \\
\hline
\end{tabular}

$S D$ standard deviation, BMI body mass index, mGPS modified Glasgow Prognostic Score, ECOG PS Eastern Cooperative Oncology Group Criteria Performance Status

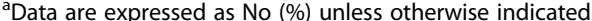

${ }^{\mathrm{b}}$ malnutrition was defined as $\mathrm{BMI}<21 \mathrm{~kg} / \mathrm{m}^{2}$ in patients aged more than

70 years old and $\mathrm{BMI}<18.5 \mathrm{~kg} / \mathrm{m}^{2}$ in patients aged less than 70 years old

coverweight was defined as $\mathrm{BMl}>25 \mathrm{~kg} / \mathrm{m}^{2}$

${ }^{\mathrm{d}} 6$ missing data

eneurotoxic regimens: 5FU + IRINOTECAN+OXALIPLATIN, 5FU +

OXALIPLATIN,GEMCITABINE + OXALIPLATIN; VP16-CISPLATINE

Chemotherapy-induced dose-limiting toxicities (DLT) and dose-limiting neurotoxicity (DLN)

Data were prospectively recorded in medical file at each hospital stay. Chemotherapy-induced DLT (all non-neurological toxicities) were defined as any toxicity leading to dose reduction (temporary or permanent), treatment delays or permanent treatment discontinuation. Chemotherapy-induced DLN was defined as permanent peripheral neuropathy (Levi scale grade 2 or 3 ) leading to dose reduction or permanent treatment discontinuation. DLN and progressive disease as the cause of treatment termination were not considered as DLT. Pre-therapeutic dose adaptation was defined as an initial dose reduction by individual clinical appreciation taking into account patient profile (age, ECOG Performance Status (PS), organ failure, malnutrition or mGPS). Malnutrition was defined as $\mathrm{BMI}<21 \mathrm{~kg} / \mathrm{m}^{2}$ in patients aged more than 70 years old and BMI $<18.5 \mathrm{~kg} / \mathrm{m}^{2}$ in patients aged less than 70 years old [26].

\section{Statistical analysis}

Data were described using mean \pm standard deviation for quantitative variables and numbers (percentage) for qualitative variables.

The survival curves were established by the Kaplan-Meier method. Prognostic factors were identified by univariate analysis using the log rank tests and by multivariate analysis using a Cox proportional hazard model. Factors significant at the 0.20 level in univariate analysis were included in a stepwise regression multivariate analysis with entry and removal limits set at 0.20 . Concerning analysis of factors associated with chemotherapy-induced DLN, neurotoxic chemotherapy was not included in multivariate analysis because of one strata has no event (convergence wasn't satisfied) and BMI was not included in multivariate analysis because of multicollinearity. 
Comparisons between subgroups of patients were performed using Chi 2 test, Fisher's exact test, Student's t test or Wilcoxon test, as appropriate.

All analyses were performed using SAS version 9.4 (SAS Institute Inc., Cary, NC, USA).

\section{Results}

\section{Description of the population}

Among the 201 consecutive patients of the FIGHTDIGO study, 45 were chemotherapy-naïve. Characteristics of those 45 patients are presented in Table 1. Mean age was $66.2 \pm 12.3$ years. Colorectal cancer was the most frequent digestive location $(n=22[51.2 \%])$. The majority of participants were treated for localized tumor $(n=20$ [44.4\%]). Median follow up was 167 days [0-189], corresponding to a median number of 10 [0-18] ambulatory hospitalizations for chemotherapy. Eighty-four percent $(n=38)$ of the patients underwent chemotherapy alone and $16 \%$ $(n=7)$ underwent combination of chemotherapy and biotherapy. The majority of anticancer drugs were potentially neurotoxic $(n=31[68.7 \%])$ and the most frequently received chemotherapy regimen was FOLFOX (5FU, leucovorin plus oxaliplatin). Fourteen patients (31.1\%) were overweight $\left(\mathrm{BMI}>25 \mathrm{~kg} / \mathrm{m}^{2}\right)$. Eleven patients $(24.4 \%)$ had dynapenia.

\section{Chemotherapy-induced DLT}

Results are shown in Table 2. DLT occurred in 22 patients $(48.9 \%)$. Most of DLT was digestive (63.6\%) (diarrhea $(n=8)$, mucositis $(n=4)$, vomiting $(n=2))$ and hematological $(36.4 \%)$ (thrombopenia $(n=4)$, neutropenia $(n=3)$ and febrile neutropenia $(n=1))$. None characteristic was significantly associated with DLT in univariate analysis. There was no significant association between dynapenia and DLT $(n=7$ (31.8\%) in DLT group versus $n=4(17.4 \%) ; p=0.62)$.

\section{Chemotherapy-induced DLN}

Results are shown in Table 3. A total of 19 patients experienced DLN (42.2\%). Sensitive neuropathy occurred exclusively in patients receiving neurotoxic chemotherapy $(n=19(63.3 \%)$ in DLN group versus $n=0(0 \%)$ in other patients; $p<0.001)$. Stomach, biliary tract and small intestine cancers received exclusively neurotoxic chemotherapy. In univariate analysis, tumoral location in stomach, biliary tract or small intestine $(p=0.02)$, ECOG PS 1 or $2(p=0.04)$, BMI $(p=0.048)$ and overweight $(p=0.02)$ were associated with DLN. No significant association with age, mGPS, malnutrition or stage were observed. Four variables were included in multivariate analysis: dynapenia, ECOG PS, overweight and tumoral location (stomach, biliary tract or small intestine). In multivariate analysis, dynapenia and tumoral location were identified as risk factors for DLN $(\mathrm{HR}=3.5[1.3$;
9.8]; $p=0.02$ and $\mathrm{HR}=3.6[1.3 ; 10.0] ; p=0.01$, respectively). Association between dynapenia and DLN is shown in Fig. 1. ECOG PS 1 or 2 appeared as a protective factor of DLN $(\mathrm{HR}=0.3[0.1 ; 0.9] ; p=0.03)$.

\section{Pre-therapeutic chemotherapy dose adaptation}

Table 4 showed results. In univariate analysis, no significant association between pre-therapeutic dose adaptation and ECOG PS 1 or $2(p=0.70)$ or malnutrition ( $p=0.64$ ) were found. The 2 patients with ECOG PS 2 had a pre-therapeutic adaptation.

\section{Discussion}

To our knowledge, this prospective study is the first to show that pre-therapeutic dynapenia (low HGS testing with a Jamar dynamometer) could be predictive of chemotherapy-induced DLN in digestive cancer patients. Majority of participants received a neurotoxic regimen which enhanced these findings. Stomach, biliary tract and small intestine cancers were significantly associated with DLN in unadjusted and adjusted analysis because of receiving exclusively neurotoxic chemotherapy. There was no association of dynapenia with chemotherapy-induced DLT. This might be explained by several elements: efficacy of supportive cares, good safety profile of chemotherapy regimen in digestive cancers (as FOLFOX regimen [27]), favorable prognostic profile of our population [1] and a small sample size. Conversely, in a pilot study in 112 older newly diagnosed cancer patients with a minority of digestive cancer $(n=20)$, low grip strength predicted toxicity at 3 months [28]. In our study, as none significant association of chemotherapy-induced DLT could be detected with age, malnutrition, BMI, mGPS and stage, and ECOG PS 1 or 2 was found to be a protective factor of DLN, heterogeneity of population and pre-therapeutic dose adaptation of chemotherapy might be an explanation of discrepancies. Most of oncology trials excluded patients with ECOG PS > 1 [29-31]. A bad condition at inclusion could be a bias for evaluation and limit the scope of potentially tested treatments. Modified GPS is an inflammation-based prognostic score. It has been shown to be correlated with mortality in colon cancer [32] influenced by malnutrition and predicting toxicity [33]. In present study, a small sample size with $\mathrm{mGPS}=2$ and/or ECOG PS 2 might be responsible of non-significant results.

Cancer cachexia is a recent concept that has been defined with the emergence of the body composition consideration in oncology [18] [34]. Prado et al. has reported the association of body composition with chemotherapy-induced DLT in stage II-III colon cancer patients treated with 5FU and leucovorin [35]. These results had consequences on phase I studies with many works on relationship between sarcopenia/body composition and DLT [9, 11]. Body 
Table 2 Factors associated with chemotherapy-induced Dose-Limiting Toxicities (DLT)

\begin{tabular}{|c|c|c|c|}
\hline Characteristics $^{a}$ & $\begin{array}{l}\text { DLTs } \\
(n=22)\end{array}$ & $\begin{array}{l}\text { No DLT } \\
(n=23)\end{array}$ & $\begin{array}{l}\text { Univariate analysis } \\
p \text { value }\end{array}$ \\
\hline Maximum handgrip strength, mean $\pm S D$ & $26.1 \pm 7.2$ & $31.2 \pm 10.8$ & 0.21 \\
\hline Dynapenia & $7(31.8)$ & $4(17.4)$ & 0.62 \\
\hline Age, mean \pm & $66.2 \pm 13.5$ & $66.3 \pm 11.4$ & 0.53 \\
\hline ECOG PS & & & 0.90 \\
\hline 0 & $6(27.3)$ & $6(26.1)$ & \\
\hline 1 & $16(72.7)$ & $15(65.2)$ & \\
\hline 2 & $0(0)$ & $2(8.7)$ & \\
\hline$m G P S^{b}$ & & & 0.12 \\
\hline $0, N(\%)$ & $11(64.7)$ & $6(35.3)$ & \\
\hline 1, N (\%) & $7(41.2)$ & $10(58.8)$ & \\
\hline $2, N(\%)$ & $2(40.0)$ & $3(60.0)$ & \\
\hline 0 & $11(55.0)$ & $6(31.6)$ & \\
\hline 1 & $7(35.0)$ & $10(52.6)$ & \\
\hline 2 & $2(10.0)$ & $3(15.8)$ & \\
\hline Primary tumor location & & & 0.21 \\
\hline Colon and rectum & $12(57.1)$ & $10(45.4)$ & \\
\hline Esophagus & $1(4.8)$ & $2(9.1)$ & \\
\hline Stomach & $1(4.8)$ & $4(18.2)$ & \\
\hline Biliary tract & $1(4.8)$ & $0(0)$ & \\
\hline Pancreas & $6(28.6)$ & $3(13.6)$ & \\
\hline Small intestine & $0(0)$ & $1(4.5)$ & \\
\hline Neuroendocrine tumor & $0(0)$ & $2(9.1)$ & \\
\hline Stage & $22(48.8)$ & $23(51.2)$ & 0.77 \\
\hline Local, N (\%) & $11(55.0)$ & $9(45.0)$ & \\
\hline Locally advanced, N (\%) & $3(50.0)$ & $3(50.0)$ & \\
\hline Metastatic, N (\%) & $8(42.1)$ & $11(57.9)$ & \\
\hline Local & $11(50)$ & $9(39.1)$ & \\
\hline Locally advanced & $3(13.6)$ & $3(13.0)$ & \\
\hline Metastatic & $8(36.4)$ & $11(47.8)$ & \\
\hline $\mathrm{BMI}$, mean $\pm \mathrm{SD}, \mathrm{kg} / \mathrm{m} 2$ & $22.7 \pm 3.9$ & $23.8 \pm 4.3$ & 0.64 \\
\hline BMI categories & & & 0.36 \\
\hline Malnutrition ${ }^{c}$ & $5(22.7)$ & $2(8.7)$ & \\
\hline Normal & $11(50.0)$ & $13(56.5)$ & \\
\hline Overweight $^{d}$ & $6(27.3)$ & $8(34.8)$ & \\
\hline
\end{tabular}

SD standard deviation, BMI body mass index, mGPS modified Glasgow Prognostic Score, ECOG PS Eastern Cooperative Oncology Group Criteria Performance Status ${ }^{a}$ Data are expressed as No (\%) unless otherwise indicated

${ }^{\mathrm{b}} 6$ missing data

${ }^{c}$ malnutrition was defined as $\mathrm{BMI}<21 \mathrm{~kg} / \mathrm{m}^{2}$ in patients aged more than 70 years old and $\mathrm{BMI}<18.5 \mathrm{~kg} / \mathrm{m}^{2}$ in patients aged less than 70 years old

${ }^{\mathrm{d}}$ overweight was defined as $\mathrm{BMI}>25 \mathrm{~kg} / \mathrm{m}^{2}$

composition and sarcopenia seem to be prognostic of enhanced chemotherapy and targeted therapy toxicity $[7,8$, $10,11,13]$, and more recently with immune checkpoint inhibitors such as anti-CTLA-4 (ipilimumab) [12].

Lean Body Mass (LBM) was associated with chemotherapy-induced DLT and DLN in patients with colon cancers treated with FOLFOX regimen [36]. Neurotoxicity affects $80 \%$ of patients and becomes chronic in $15-20 \%$ of cases, sometimes irreversibly [27]. A recent systematic review [37] has reported the impact of acute oxaliplatin-induced neuropathy and necessity of a large prospective study to established 
Table 3 Factors associated with chemotherapy-induced Dose-Limiting Neurotoxicity (DLN)

\begin{tabular}{|c|c|c|c|c|c|}
\hline \multirow[t]{2}{*}{ Characteristics $^{a}$} & \multirow{2}{*}{$\begin{array}{l}\text { DLNs } \\
(n=19)\end{array}$} & \multirow{2}{*}{$\begin{array}{l}\text { No DLN } \\
(n=26)\end{array}$} & \multirow{2}{*}{$\begin{array}{l}\text { Univariate analysis } \\
p \text { value }\end{array}$} & \multicolumn{2}{|c|}{ Multivariate analysis $^{d}$} \\
\hline & & & & $\mathrm{HR}[95 \% \mathrm{Cl}]$ & $p$ value \\
\hline Maximum handgrip strength, mean \pm SD & $29.1 \pm 10.3$ & $28.5 \pm 9.1$ & 0.64 & & \\
\hline Dynapenia & & & 0.13 & & 0.02 \\
\hline No & $12(63.2)$ & $22(84.6)$ & & 1 & \\
\hline Yes & $7(36.8)$ & $4(15.4)$ & & $3.5[1.3 ; 9.8]$ & \\
\hline Age, mean $\pm S D$ & $65.9 \pm 11.5$ & $66.5 \pm 13.1$ & 0.89 & & \\
\hline ECOG PS & & & 0.04 & & 0.03 \\
\hline 0 & $8(42.1)$ & $4(15.4)$ & & 1 & \\
\hline 1 or 2 & $11(57.9)$ & $22(84.6)$ & & $0.4[0.2 ; 0.9]$ & \\
\hline $\mathrm{mGPS}^{\mathrm{b}}$ & & & 0.39 & & \\
\hline 0 & $8(50.0)$ & $9(39.1)$ & & & \\
\hline 1 & $8(50.0)$ & $9(39.1)$ & & & \\
\hline 2 & $0(0.0)$ & $2(21.7)$ & & & \\
\hline Primary Tumor location & & & 0.02 & & 0.01 \\
\hline Stomach - Biliary tract - Small Intestine & $6(31.6)$ & $1(4.2)$ & & $3.6[1.3 ; 10.0]$ & \\
\hline Other location & $13(68.4)$ & $23(95.8)$ & & 1 & \\
\hline Stage & & & 0.49 & & \\
\hline Local & $10(52.6)$ & $10(38.5)$ & & & \\
\hline Locally advanced & $1(5.3)$ & $5(19.2)$ & & & \\
\hline Metastatic & $8(42.1)$ & $11(42.3)$ & & & \\
\hline $\mathrm{BMl}$, mean $\pm \mathrm{SD}, \mathrm{kg} / \mathrm{m} 2$ & $23.9 \pm 3.4$ & $22.8 \pm 4.5$ & 0.048 & & \\
\hline Overweight, No. $(\%)^{c}$ & & & 0.02 & & \\
\hline Yes & $9(47.4)$ & $5(19.2)$ & & & \\
\hline No & $10(52.6)$ & $21(80.8)$ & & & \\
\hline
\end{tabular}

SD standard deviation, HR Hazard Ratio, BMI body mass index, mGPS modified Glasgow Prognostic Score, ECOG PS Eastern Cooperative Oncology Group Criteria Performance Status

${ }^{a}$ Data are expressed as No (\%) unless otherwise indicated

${ }^{\mathrm{b}} 6$ missing data

coverweight was defined as $\mathrm{BMI}>25 \mathrm{~kg} / \mathrm{m}^{2}$

${ }^{d}$ four variables were included in multivariate analysis: dynapenia, ECOG PS, overweight and tumoral location, neurotoxic chemotherapy was not included in multivariate analysis because of one strata has no event (convergence wasn't satisfied)

better preventive guidelines. In 2 cohorts of colorectal cancer patients treated with oxaliplatin, Ali et al. [36] reported that overall DLT, and specifically oxaliplatin-induced neuropathy, occurred mostly in patients who receive $>3.09 \mathrm{mg} /$ oxaliplatin $/ \mathrm{kg}$ LBM. One study is ongoing to determine whether the oxaliplatin dose normalization based on the LBM index can prevent or reduce neurotoxicity associated with oxaliplatin, for colorectal cancer patients treated in adjuvant with FOLFOX regimen (LEANOX trial NCT03255434). Our findings might be an additional argument for this hypothesis. Dynapenia, which is the first step toward sarcopenia, may represent an interesting tool to estimate sarcopenia / LBM [38]. It might be a more easily accessible predictive marker for oxaliplatin dose adaptation because patients with low muscle mass behave like patients "overdosed" with chemotherapy resulted in dose-limiting toxicities, independently of the patient's weight.

In present study, there were $31 \%$ of overweight patients. Recently, it has been reported that overweight sarcopenic patients experienced more DLT [12, 39, 40] than overweight patients with normal LBM. A potential explanation could be an altered volume distribution, metabolism or clearance in lean tissue of anticancer drugs in these patients [41]. Dose of cytotoxic drugs has been shown to be correlated with LBM [35]. These findings suggest a new paradigm in the future: body composition measurement leading to dose adaptation of antineoplastic agents.

Gray et al. have reported a prediction model used to identify sarcopenia based on parameters of functional fitness [42]. Correlation between measure of dynapenia 


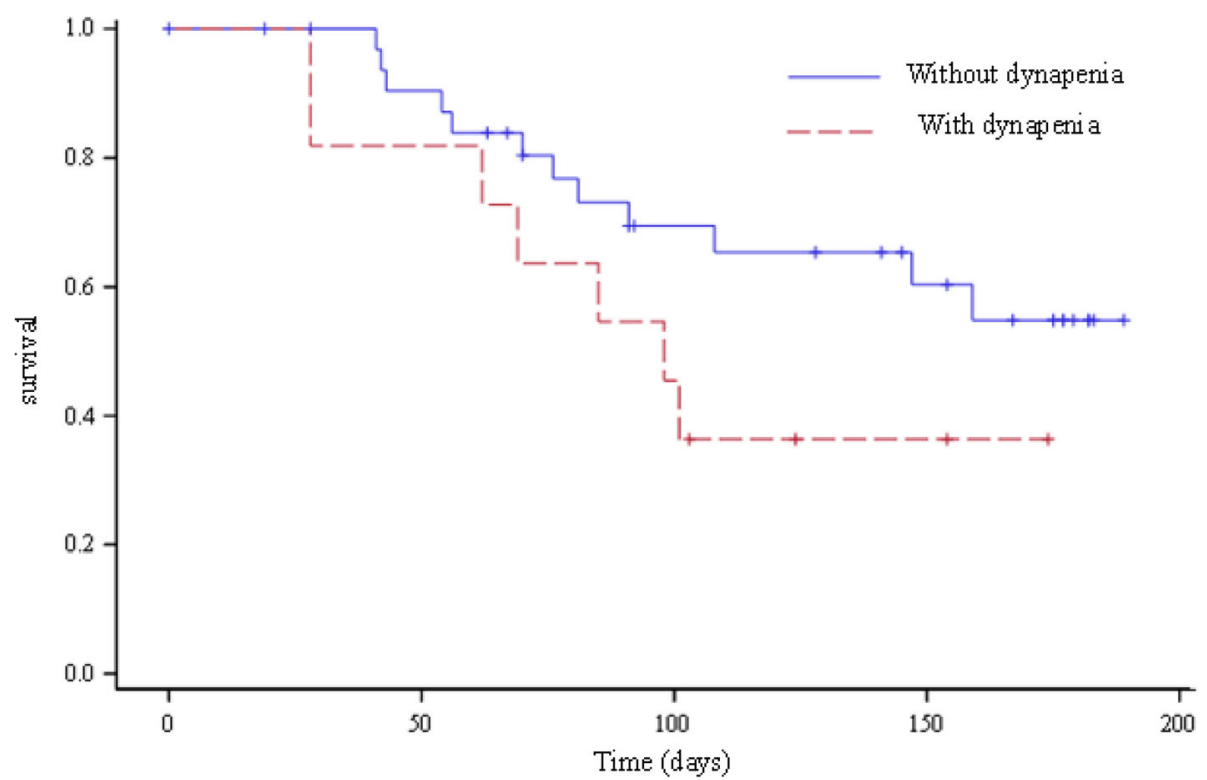

Fig. 1 Association between dynapenia and Dose-Limiting Neurotoxicity (DLN). $p=0.002$. Hazard Ratio = 3.5 [1.3; 9.8]

and skeletal muscle index by computed tomography in a cancer population are being evaluated in a further ancillary analysis of FIGHTDIGO study.

HGS measure is a useful low-cost method [23] which could improve clinical practice by stratifying frailty patients who experienced more DLN. More relevant nutritional and adapted physical activity programs might be needed.

A major limitation of this ancillary study is the size of cohort with only 45 patients with various type of digestive cancers and heterogeneous chemotherapy regimens. Several aspects of using the Jamar dynamometer may require further investigation. Many studies are attempting to determine cut points for dynapenia with respect to age, sex, and ethnic group [5, 43, 44]. The HGS dynamometer thresholds remain undetermined for cancer patients.

Table 4 Factors associated with dose adaptation

\begin{tabular}{llll}
\hline $\begin{array}{l}\text { Characteristics } \\
\text { ECOG PS }\end{array}$ & $\begin{array}{l}\text { Dose } \\
\text { adaptation }\end{array}$ & $\begin{array}{l}\text { Dose } \\
\text { complete }\end{array}$ & $\begin{array}{l}\text { Univariate analysis } \\
p \text { value }\end{array}$ \\
0 & $2(16.7)$ & $10(83.3)$ & 0.70 \\
1 or 2 & $8(24.2)$ & $25(75.8)$ & \\
Malnutrition & $2(28.6)$ & $5(71.4)$ & 0.64 \\
\hline
\end{tabular}

${ }^{\mathrm{a}}$ Data are expressed as No (\%) unless otherwise indicated ECOG PS Eastern Cooperative Oncology Group Criteria Performance Status, SD standard deviation; malnutrition was defined as $B M l<21 \mathrm{~kg} / \mathrm{m}^{2}$ in patients aged more than 70 years old and $\mathrm{BMI}<18.5 \mathrm{~kg} / \mathrm{m}^{2}$ in patients aged less than 70 years old

\section{Conclusions}

In conclusion, digestive cancer patients with pre-therapeutic dynapenia seemed to experience more chemotherapy-induced DLN. This small cohort study suggests that dynapenia could be a predictive marker of chemotherapy-induced DLN. Further studies need to be performed to obtain more definitive data. Since dynapenia is the first step toward sarcopenia, HGS routine measurement may be a way to screen patients with frailty marker who require dose adaptation of antineoplastic agents and adapted physical activity programs to prevent chemotherapy-induced neurotoxicity.

\section{Abbreviations}

BMI: Body Mass Index; BSA: Body Surface Area; DLN: Chemotherapy induced Dose-Limiting Neurotoxicity; DLT: Chemotherapy-induced Dose-Limiting Toxicities; ECOG PS: Eastern Cooperative Oncology Group Criteria Performance Status; FOLFOX: 5FU, leucovorin + oxaliplatin; HGS: Handgrip Strength; HR: Hazard Ratio; LBM: Lean Body Mass; mGPS: Modified Glasgow Prognostic Score; SD: Standard Derivation; UMA-CH: Ambulatory Digestive Cancer Unit

Availability of data and materials

The datasets used and/or analysed during the current study are available from the corresponding author on reasonable request.

\section{Authors' contributions}

Authors: DB, MAO, CB, CM, MP, JM, MB, YR, BT, FS, EB, OB. Conceptualization: $D B, M A O, E B, O B, C M, M P, Y R, J M, M B, B T$ and FS. Methodology: DB, MAO, CB and $\mathrm{OB}$. Validation: $\mathrm{DB}, \mathrm{MAO}, \mathrm{CB}, \mathrm{CM}, \mathrm{MP}, \mathrm{JM}, \mathrm{YR}, \mathrm{MB}, \mathrm{BT}, \mathrm{FS}, \mathrm{EB}$ and $\mathrm{OB}$. Writing original draft: DB. Data management and statistical analysis: $C B$. Investigation: $C M, M P, J M, Y R, M B, B T, F S$ and $O B$. Supervision: $C B, E B$ and $O B$. Writing-review and editing: $M A O, C B, C M, M P, J M, Y R, M B, B T, F S, E B$ and $O B$. All authors read and approved the final manuscript.

\section{Ethics approval and consent to participate}

Informed written consent was obtained for each enrolled patient in the trial. The FIGHTDIGO study was approved by the ethics committee (Committee 
for the Protection of Person EST I DIJON, 25 March 2016) and was registered in Clinicaltrials.gov (NCT02797197).

\section{Consent for publication}

none

\section{Competing interests}

Damien Botsen reports personal fees from Pierre Fabre and non-financial support from GlaxoSmithKline, Novartis, Chugai, and Amgen outside the submitted work

Camille Mazza reports personal fees from Pierre Fabre outside the submitted work.

Mathilde Brasseur reports personal fees from Bayer and non-financial support from Pierre Fabre, Novartis, Amgen, Roche, and AbbVie outside the submitted work.

Olivier Bouche reports grants from Roche, personal fees from Roche, grants from Pierre Fabre, personal fees from Pierre Fabre, personal fees from Amgen, personal fees from Bayer, personal fees from Lilly, personal fees from Merck, personal fees from Novartis, outside the submitted work.

Yohann Renard reports grants from Bard and Allergan, outside the submitted work. Marie-Amélie Ordan, Marine Perrier, Johanna Moreau, Coralie Barbe, Florian Slimano, Barbara Taillière, Eric Bertin: The authors declare that they have no competing interests.

\section{Publisher's Note}

Springer Nature remains neutral with regard to jurisdictional claims in published maps and institutional affiliations.

\section{Author details}

${ }^{1}$ Ambulatory Cancer Unit, Reims University Hospital, Robert Debré Hospital, rue du Général Koenig, 51100 Reims, France. ${ }^{2}$ Clinical Research Unit, Reims University Hospital, Robert Debré Hospital, rue du Général Koenig, 51100 Reims, France. ${ }^{3}$ Department of Gastroenterology and Digestive Oncology, Reims University Hospital, Robert Debré Hospital, rue du Général Koenig, 51100 Reims, France. ${ }^{4}$ Department of General and Digestive Surgery, Reims University Hospital, Reims, France. ${ }^{5}$ Artificial Nutrition Unit, Reims University Hospital, Robert Debré Hospital, rue du Général Koenig, 51100 Reims, France. ${ }^{6}$ Department of Nutrition, Endocrinology, and Diabetology, Reims University Hospital, Robert Debré Hospital, rue du Général Koenig, 51100 Reims, France.

\section{Received: 15 April 2018 Accepted: 26 September 2018}

\section{Published online: 04 October 2018}

\section{References}

1. World Health Organization. GLOBOCAN 2012: estimated cancer incidence, mortality and prevalence worldwide in 2012. http://globocan.iarc.fr/Pages/ fact_sheets_cancer.aspx. Accessed 5 Feb 2017.

2. Fearon K, Strasser F, Anker SD, Bosaeus I, Bruera E, Fainsinger RL, et al. Definition and classification of cancer cachexia: an international consensus. Lancet Oncol. 2011;12(5):489-95.

3. Manini TM, Clark BC. Dynapenia and aging: an update. J Gerontol A Biol Sci Med Sci. 2012;67(1):28-40.

4. Evans WJ, Campbell WW. Sarcopenia and age-related changes in body composition and functional capacity. J Nutr. 1993;123(2 Suppl):465-8.

5. Cruz-Jentoft AJ, Baeyens JP, Bauer JM, Boirie Y, Cederholm T, Landi F, et al. Sarcopenia: European consensus on definition and diagnosis. Age Ageing. 2010:39(4):412-23.

6. Du Bois D, Du Bois EF. A formula to estimate the approximate surface area if height and weight be known. 1916. Nutr. 1989;5(5):303-11 discussion 312-13.

7. Massicotte M-H, Borget I, Broutin S, Baracos VE, Leboulleux S, Baudin E, et al. Body composition variation and impact of low skeletal muscle mass in patients with advanced medullary thyroid carcinoma treated with vandetanib: results from a placebo-controlled study. J Clin Endocrinol Metab. 2013;98(6):2401-8.

8. Huillard O, Boissier E, Blanchet B, Thomas-Schoemann A, Cessot A, BoudouRouquette $P$, et al. Drug safety evaluation of sorafenib for treatment of solid tumors: consequences for the risk assessment and management of cancer patients. Expert Opin Drug Saf. 2014;13(5):663-73.
9. Cousin S, Hollebecque A, Koscielny S, Mir O, Varga A, Baracos VE, et al. Low skeletal muscle is associated with toxicity in patients included in phase I trials. Investig New Drugs. 2014;32(2):382-7.

10. Huillard O, Mir O, Peyromaure M, Tlemsani C, Giroux J, BoudouRouquette $P$, et al. Sarcopenia and body mass index predict sunitinibinduced early dose-limiting toxicities in renal cancer patients. $\mathrm{Br} \mathrm{J}$ Cancer. 2013;108(5):1034-41.

11. Mir O, Coriat R, Blanchet B, Durand J-P, Boudou-Rouquette P, Michels J, et al. Sarcopenia predicts early dose-limiting toxicities and pharmacokinetics of sorafenib in patients with hepatocellular carcinoma. PLoS One. 2012;7(5):e37563.

12. Daly LE, Power DG, O'Reilly Á, Donnellan P, Cushen SJ, O'Sullivan K, et al. The impact of body composition parameters on ipilimumab toxicity and survival in patients with metastatic melanoma. $\mathrm{Br} J$ Cancer. 2017;116(3):310-7.

13. Prado CMM, Antoun S, Sawyer MB, Baracos VE. Two faces of drug therapy in cancer: drug-related lean tissue loss and its adverse consequences to survival and toxicity. Curr Opin Clin Nutr Metab Care. 2011;14(3):250-4.

14. Sawyer M, Ratain MJ. Body surface area as a determinant of pharmacokinetics and drug dosing. Investig New Drugs. 2001;19(2):171-7.

15. Gurney H. How to calculate the dose of chemotherapy. Br J Cancer. 2002; 86(8):1297-302.

16. Morgan DJ, Bray KM. Lean body mass as a predictor of drug dosage. Implications for drug therapy. Clin Pharmacokinet. 1994;26(4):292-307.

17. Aslani A, Smith RC, Allen BJ, Pavlakis N, Levi JA. The predictive value of body protein for chemotherapy-induced toxicity. Cancer. 2000; 88(4):796-803.

18. Cohen S, Nathan JA, Goldberg AL. Muscle wasting in disease: molecular mechanisms and promising therapies. Nat Rev Drug Discov. 2015;14(1):58-74.

19. Kilgour RD, Vigano A, Trutschnigg B, Hornby L, Lucar E, Bacon SL, et al. Cancer-related fatigue: the impact of skeletal muscle mass and strength in patients with advanced cancer. J Cachexia Sarcopenia Muscle. 2010; 1(2):177-85.

20. Norman K, Stobäus N, Smoliner C, Zocher D, Scheufele R, Valentini L, et al. Determinants of hand grip strength, knee extension strength and functional status in cancer patients. Clin Nutr Edinb Scotl. 2010;29(5):586-91.

21. Chen $\mathrm{C}-\mathrm{H}$, Null H-C, Huang $\mathrm{Y}-\mathrm{Z}$, Hung T-T. Hand-grip strength is a simple and effective outcome predictor in esophageal cancer following esophagectomy with reconstruction: a prospective study. J Cardiothorac Surg. 2011;6:98

22. Kilgour RD, Vigano A, Trutschnigg B, Lucar E, Borod M, Morais JA. Handgrip strength predicts survival and is associated with markers of clinical and functional outcomes in advanced cancer patients. Support Care Cancer. 2013:21(12):3261-70.

23. Ordan M-A, Mazza C, Barbe C, Perrier M, Botsen D, Renard Y, et al. Feasibility of systematic handgrip strength testing in digestive cancer patients treated with chemotherapy: the FIGHTDIGO study: feasibility of handgrip strength. Cancer. 2017; [Epub ahead of print].

24. Janssen I, Heymsfield SB, Ross R. Low relative skeletal muscle mass (sarcopenia) in older persons is associated with functional impairment and physical disability. J Am Geriatr Soc. 2002;50(5):889-96.

25. Prado CMM, Lieffers JR, Bowthorpe L, Baracos VE, Mourtzakis M, McCargar $\amalg$. Sarcopenia and physical function in overweight patients with advanced cancer. Can J Diet Pract. 2013;74(2):69-74.

26. Haute Autorité de Santé: Stratégie de prise en charge en cas de dénutrition protéino-énergétique chez la personne âgée. https://www.has-sante.fr/ portail/jcms/c_546549/fr/strategie-de-prise-en-charge-en-cas-de-denutritionproteino-energetique-chez-la-personne-agee. Accessed 28 Sept 2017.

27. André T, Boni C, Mounedji-Boudiaf L, Navarro M, Tabernero J, Hickish T, et al. Oxaliplatin, fluorouracil, and leucovorin as adjuvant treatment for colon cancer. N Engl J Med. 2004;350(23):2343-51.

28. Puts MTE, Monette J, Girre V, Pepe C, Monette M, Assouline S, et al. Are frailty markers useful for predicting treatment toxicity and mortality in older newly diagnosed cancer patients? Results from a prospective pilot study. Crit Rev Oncol Hematol. 2011;78(2):138-49.

29. Conroy T, Desseigne F, Ychou M, Bouché O, Guimbaud R, Bécouarn Y, et al. FOLFIRINOX versus gemcitabine for metastatic pancreatic cancer. N Engl J Med. 2011;364(19):1817-25.

30. Wagner AD, Grothe W, Behl S, Kleber G, Grothey A, Haerting J, et al. Chemotherapy for advanced gastric cancer. Cochrane Database Syst Rev. 2005;2:CD004064. 
31. Eckel F, Schmid RM. Chemotherapy in advanced biliary tract carcinoma: a pooled analysis of clinical trials. Br J Cancer. 2007;96(6):896-902.

32. Kishiki T, Masaki T, Matsuoka H, Kobayashi T, Suzuki Y, Abe N, et al. Modified Glasgow prognostic score in patients with incurable stage IV colorectal cancer. Am J Surg. 2013;206(2):234-40.

33. McMillan DC. The systemic inflammation-based Glasgow prognostic score: a decade of experience in patients with cancer. Cancer Treat Rev. 2013;39(5): 534-40.

34. Prado CMM, Maia YLM, Ormsbee M, Sawyer MB, Baracos VE. Assessment of nutritional status in cancer--the relationship between body composition and pharmacokinetics. Anti Cancer Agents Med Chem. 2013;13(8):1197-203.

35. Prado CMM, Baracos VE, McCargar LJ, Mourtzakis M, Mulder KE, Reiman T, et al. Body composition as an independent determinant of 5-fluorouracilbased chemotherapy toxicity. Clin Cancer Res Off J Am Assoc Cancer Res. 2007:13(11):3264-8.

36. Ali R, Baracos VE, Sawyer MB, Bianchi L, Roberts S, Assenat E, et al. Lean body mass as an independent determinant of dose-limiting toxicity and neuropathy in patients with colon cancer treated with FOLFOX regimens. Cancer Med. 2016;5(4):607-16.

37. Gebremedhn EG, Shortland PJ, Mahns DA. The incidence of acute oxaliplatin-induced neuropathy and its impact on treatment in the first cycle: a systematic review. BMC Cancer. 2018;18(1):410,

38. Steffl M, Musalek M, Kramperova V, Petr M, Kohlikova E, Holmerova I, et al. Assessment of diagnostics tools for sarcopenia severity using the item response theory (IRT). J Nutr Health Aging. 2016;20(10):1051-5.

39. Baracos VE, Arribas L. Sarcopenic obesity: hidden muscle wasting and its impact for survival and complications of cancer therapy. Ann Oncol Off J Eur Soc Med Oncol. 2018;29(suppl_2):ii1-9.

40. Anandavadivelan P, Brismar TB, Nilsson M, Johar AM, Martin L. Sarcopenic obesity: a probable risk factor for dose limiting toxicity during neo-adjuvant chemotherapy in oesophageal cancer patients. Clin Nutr Edinb Scotl. 2016; 35(3):724-30.

41. Antoun S, Borget I, Lanoy E. Impact of sarcopenia on the prognosis and treatment toxicities in patients diagnosed with cancer. Curr Opin Support Palliat Care. 2013;7(4):383-9.

42. Gray M, Glenn JM, Binns A. Predicting sarcopenia from functional measures among community-dwelling older adults. Age Dordr Neth. 2016;38(1):22.

43. Dodds RM, Syddall HE, Cooper R, Kuh D, Cooper C, Sayer AA. Global variation in grip strength: a systematic review and meta-analysis of normative data. Age Ageing. 2016;45(2):209-16.

44. Sampaio RAC, Sampaio PYS, Castaño LAA, Barbieri JF, Coelho HJ, Arai H, et al. Cutoff values for appendicular skeletal muscle mass and strength in relation to fear of falling among Brazilian older adults: cross-sectional study. Sao Paulo Med J Rev Paul Med. 2017:135(5):434-43.

Ready to submit your research? Choose BMC and benefit from:

- fast, convenient online submission

- thorough peer review by experienced researchers in your field

- rapid publication on acceptance

- support for research data, including large and complex data types

- gold Open Access which fosters wider collaboration and increased citations

- maximum visibility for your research: over $100 \mathrm{M}$ website views per year

At $\mathrm{BMC}$, research is always in progress.

Learn more biomedcentral.com/submissions 